Meta

Journal des traducteurs

Translators' Journal

\title{
Incongruency in Discourse: A Violation of the "Cooperative Principle"?
}

\section{Bertram A. Okolo}

Volume 41, numéro 3, septembre 1996

URI : https://id.erudit.org/iderudit/003762ar

DOI : https://doi.org/10.7202/003762ar

Aller au sommaire du numéro

Éditeur(s)

Les Presses de l'Université de Montréal

ISSN

0026-0452 (imprimé)

1492-1421 (numérique)

Découvrir la revue

Citer cet article

Okolo, B. A. (1996). Incongruency in Discourse: A Violation of the "Cooperative Principle"? Meta, 41(3), 378-388. https://doi.org/10.7202/003762ar
Résumé de l'article

Lorsqu'on la considère en tant qu'acte de behaviorisme verbal destiné à produire un sens contradictoire dans un discours, l'incongruité semble violer le "principe de coopération" de Grince supposé s'appliquer aux conversations de tous les jours. Cet article examine des échanges verbaux réels et discute des facteurs régissant la tolérance d'éléments incongrus lors d'interactions conversationnelles; on examine des aspects interculturels des actes de comportement incongrus et leurs implications traditionnelles pour conclure que la soumission stricte au "principe de coopération" est restreinte à certains types de discours. 


\title{
INCONGRUENCY IN DISCOURSE: A VIOLATION OF THE "COOPERATIVE PRINCIPLE"?
}

BERTRAM A. OKolo

University of Benin, Benin City, Nigeria

\begin{abstract}
Résumé
Lorsqu'on la considère en tant qu'acte de behaviorisme verbal destiné à produire un sens contradictoire dans un discours, l'incongruité semble violer le "principe de coopération» de Grince supposé s'appliquer aux conversations de tous les jours. Cet article examine des échanges verbaux réels et discute des facteurs régissant la tolérance d'éléments incongrus lors d'interactions conversationnelles; on examine des aspects interculturels des actes de comportement incongrus et leurs implications traductionnelles pour conclure que la soumission stricte au «principe de coopération» est restreinte à certains types de discours.
\end{abstract}

\begin{abstract}
Incongruency, when regarded as a verbal behavioral act that functions to create contradictory meanings in discourse, seems to violate aspects of the Gricean "Cooperative Principle" that are supposed to guide our every-day conversational encounters. With the aid of actual examples, this paper looks at incongruent conversational exchanges and discusses the factors governing their toleration in conversational interaction, the cross-cultural aspects of incongruent behavioral acts, their translational implications, and suggests that strict observances of the "Cooperative Principle" are restricted to particular types of discourses.
\end{abstract}

\section{INTRODUCTION}

Although we engage in speech everyday, our understanding of what verbal communication involves and how it works tends to be rather naive and intuitive. In the same way as many people suffer from emasculation in their emotional life, so we users of langage suffer a concomitant emasculation in the quality of our verbal communication, in our ability to use langage as a mode of interpersonal contact and cooperation.

Most of the problems conversational partners encounter in communication are traceable to incongruency within interpersonal transaction. Incongruency is used here in its traditional sense to mean things that don't fit, different or disjunctive from, or contradictory to one another. In discourses, verbal or non-verbal behavioral acts in an exchange are incongruent when they function to create meanings that are in some way contradictory. In other words, if what you said or did was incongruent with how you said or did it, the meaning created by what you said or did contradicts the meaning implied by what you said or did. Therefore, if two or more elements in a transaction create contradictory meanings, one or both of the participants will find it difficult to respond and adapt to each other's communicative behaviour. If the participants have difficulty adapting, they will have difficulty maintaining communicative balance which either results in breakdown in communication or in disharmony in interpersonal relationships. 
This study is an attempt to describe incongruency as observed in conversational interactions. In my explication, I shall rely on psychological evidence-people's attitudes towards what is said in a given context-, and on grammatical evidence-what actually does get said. Utilizing the insights gleaned from communication theorists and linguists, I shall examine some areas where incongruent discourses are common, to what extent Gricean Cooperative Principle can handle such discourses and how interlocutors are able to interpret them. Finally, I shall discuss the cross-cultural and translational implications of such behavioral acts.

\section{THEORETICAL BACKGROUND}

Remarkable progress has been made in the study of communication and conversational behaviour. Initially, communication theory was primarily speaker-oriented where emphasis was based on how the sender must structure a message in order to achieve the desired result, with little or no attention paid to the reciever of the message (Smith and Williamson 1977). However, since communication is a two-way process, it became obvious that there was need for the receiver to feed back to the sender certain cues about the reception of the message if a successful communicational exchange is to be realized. In other words, both parties in a communication situation are participating simultaneously, perceiving each other, and are involved in making adjustments to messages exchanged. Thus, we can now attempt to describe the complexities of communication process simply and directly, in a real life situation.

The study of discourse has been generating interest in linguistic circles in recent times. Some of the linguists interested in discourse analysis have relied on a number of concepts and ideas developed by philosophers-ideas and concepts such as Speech Act, Illocutionary Force, Performative, etc. These concepts have been extended to the study of conversational organization. In particular, the ideas of Paul Grice, as set forth in his lectures Logic and Conversation (1975), have been widely used. Though Grice is primarily a Speech Act philosopher rather than a linguist as such, his ideas have had an enormous impact on linguistic analyses of discourses.

Grice's work can be seen as an attempt to clarify and correct the traditional Austinian view of attaching appropriateness conditions to a word or phrase as aspects of its meaning or sense (Pratt 1977). In particular, Grice tries to draw up general rules governing all conversations, and indeed, all goal-directed cooperative human behaviour by demonstrating that many cases of inappropriateness which have previously been analysed as violations of conditions governing the use of a particular word or expression should actually be viewed as violations of more general rules of langage use which apply to all conversations regardless of subject matter. Once these general rules are specified and isolated, Grice contends, many of the appropriateness conditions previously attached to individual words or phrases as semantic features will become unnecessary. The fact that conversations normally exhibit some degree of coherence and continuity suggests that our conversational behaviour is governed by a general principle which participants will be expected to observe. Grice calls this the Cooperative Principle.

He then proposes four sets of conversational maxims which, according to him, apply universally. Two of these maxims will be relevant to this discussion. One is a maxim of manner: "avoid obscurity of expression; avoid ambiguity" (p. 46), and the other is that of cooperation: "make your conversational contribution such as is required, at the stage at which it occurs, by the accepted purpose or direction of the talk exchange in which you are engaged" (p. 45). These rules can be understood as general appropriateness conditions that participants in a speech exchange normally assume to be in force. A 
participant in a speech exchange takes it for granted that his interlocutor shares a knowledge of the rules, is trying to observe them, and expects the same of him.

Although Grice appends two important qualifications to his rule schema: that the list he offers is not expected to be complete, and that the maxims need to be generalized to allow for such general purposes as influencing or directing the actions of others, yet, the maxims are anything but iron-clad. In fact, as Pratt (1977) would say, they are honoured as often in the breach as in the observance. First, there are speech situations where participants intentionally (or unintentionally) violate the maxims for greater communicative effects. Secondly, Grice assumes equality of dialogic roles in the application of his conversational maxims. But it is hardly the case that equality of dialogic roles are maintained in all real life conversational encounters. Interactional roles can be affected by complementarity and symmetricality of the relationship existing between the interactants. In symmetrical relationships, the interactants perceive themselves as equals within the transaction, while in complementary relationships there exists an inequality between them-a hierarchy in which one is superior to the Other in some sense. Furthermore, the same people can maintain a diversity of complementary and symmetrical relationships in an encounter depending on the roles they assume in various social situations. For example, as peers, there could exist a symmetrical relationship between them, but as teacher-student or doctor-patient, a complementary relationship is assumed. Therefore, if equality of dialogic roles must obtain in all conversational behaviours, then, it will amount to a restriction of the range of conversational interaction.

However, one of the virtues of Grice's model (particularly of the caveat he appends) is that it provides an opportunity of describing the breaches as well-the area in which this study is centred. Most incongruencies observable in our daily conversational encounters run counter to Gricean maxims, and in what follows, I shall examine some situations where these are common.

\section{INCONGRUENCIES IN DISCOURSE}

Incongruency in discourse may occur at any level: between the content and the metacommunicative levels of the message; between different message systems employed in the exchange-there may be a discrepancy between language and gesture, between gesture and space, or even between language and space; and there may be incongruency between the perspectives of the interactants which give rise to certain kinds of behaviour. Or the incongruency may arise from a complex interaction of all these factors. Here, I shall cite some few illustrative examples that seem to contradict Gricean Cooperative Principle in conversational behaviour.

\section{CONTEXTUAL INCONGRUENCY}

Sometimes a participant in a conversation may assume a role that does not fit into the context of the conversational exchange, and this, no doubt, can cause serious communication problems, leading to violations of conversational maxims. The following simple episode can serve as an illustration.

One of the High Schools in Nigeria recently celebrated its golden jubilee anniversary. The grand finale was a gala dance at which eminent personalities (including the current principal of the institution) were present. The National President of the Old Students Association chaired at the occasion. As soon as the floor was declared open by the chairman, dancing partners rushed to the floor of the jam-packed auditorium to secure spaces. It is not unusual on such occasions for males to excuse ${ }^{1}$ females for a dance. The current principal of the school, himself an old boy, tried to do so to a girl dancing with 
one of his students, and the following reconstructed exchange took place ( $\mathrm{P}$ stands for the principal, $\mathrm{G}$ for the girl and $\mathrm{S}$ for the student).

$P$ : (to G) Excuse me, can I dance with you?

$\mathrm{G}:$ (silent)

$\mathrm{S}$ : (interrupting) No, I still want to dance with her.

P: What do you mean? How dare you say that?

S: I brought her here; go and dance with your wife.

P: You are stupid. I'm going to teach you a lesson (walks away angrily).

In our culture, and within the context of principal-student relationship in a normal school setting, the power differential inherent in principal-student roles (apart from other relationship-defining parameters) will be sufficient to constrain the student from responding rather sharply to the principal's request as he did in the above context. In such a situation non-cooperation will be considered recalcitrant for the principal possesses the power to carry out his threats.

But considering the context which we are dealing with, where the power dimension is irrelevant, cooperation should not be assumed, hence the student's aggressive verbal behaviour. The principal's remarks and threats are incongruent because equality of participation rather than power differential should be the expected guiding rule of interaction in this context where every participant possesses the right to release or refuse the release of a partner irrespective of the status of the requester. Cooperation may, however, have been possible had the principal recognized the co-equality of his student in the context and made his request with that understanding in mind. And even if the principal failed in spite of his respectful approach, his understanding of the limitations of his power in the context of a gala night, would have prepared him to accept the possibility of noncooperation, and this would have helped in subduing his threatening remarks. Therefore, his assumption of a role incompatible with the context lead to the seeming violation by his student of conversational and relationship-defining rules of interaction.

\section{INCONGRUENCY IN ROLES}

Problems in interpersonal communication can occur when one of the partners assumes a role that is incongruent. Interactants are usually aware of the nature of their respective roles in an exchange, and it is the observance of this role that contributes to the rule-governed nature of conversations. When a breach occurs in role relationship, communication difficulties arise unless the roles are redefined. Let me use this episode to illustrate this.

Mother's Day is usually a big festive occasion for women in the Anglican Communion in Nigeria. On one of such occasions, my mother was talking to our housemaid in an unusually friendly manner, even going to the extent of suggesting that she dance to a tape-recorded favourite Mother's Day tune-Mother Is Supreme with her. Naturally, the maid felt surprised and shy, apparently finding it difficult to respond to my mother's friendliness. Realizing her role in the relationship, it was not easy to respond to my mother as a friend, but rather as an employer. My mother got angry and chided her: "Stop behaving as if you are not part of this family; today is Mother's Day." At this point, the maid relaxed, got up, and started dancing and sharing jokes with her as if they were equals.

The maid's initial non-responsive behaviour may be attributed to incongruency between her role as a maid and another role as a friend which my mother was seeking. Change of roles implies change of conversational relationship-defining parameters. Conscious of the role relationships that exist between her and my mother, one would really not expect the maid to respond to my mother's invitation without violating the 
relationship-defining parameters. Yet, her failure to respond meant that she had violated the cooperative principle, which infuriated my mother. It was my mother's rebuke that helped in redefining the role relationship between them, and the maid realizing this, immediatly adapted to this new role. Therefore, incompatibility in roles results in a violation of the implicit rules that govern conversational behaviour; but as soon as these roles are redefined, cooperation becomes possible, restoring normal healthy and increased productive interaction.

\section{INCONGRUENCY BETWEEN MESSAGE SYSTEMS}

Among the characteristics of human speech is the fact that most verbal behaviours are accompanied by such other communicative acts as gestures, silence, or even manipulation of space. Goldman-Eisler (1958); Henderson, Goldman-Eisler and Skarbek (1966); Butterworth and Beatie (1978), among others, have demonstrated that arm and hand movements are intimately linked with the process of speech production in such a way that they are rythmically timed with speech.

People often express one meaning with their language and another with their gestures. If a person with whom one is communicating uses multiple message systems that generate incongruency, rules of conversation are violated thus creating problems in conversation.

My uncle's wife was very fond of me at the initial part of my High School years. She encouraged me to study harder, made sure I was given enough pocket money when returning to my boarding school (sometimes she supplemented whatever I was given), visited me once in a while at school replenishing my provision stock, and bought me special gifts for any school term during which I either maintained my previous grades or improved on them. In fact, the anticipation of these generosities inspired me to work harder.

At the end of one Christmas term, she was the first person to see me alight from the bus. She ran towards me with open arms for a hug and kiss, but I unconsciously shoved her away. Feeling hurt, she stepped backwards, her arms folded, looked at me for a moment and said: "Bertram, you don't like my hugging you?" I replied rather apologetically: "Not that, I like you very much." My reply didn't help much, for she walked back into the house without even helping me with my luggage. As I observed over time, she became less demonstrative of her affection. Frankly speaking, had it been possible to turn the clock back and avoid my uncooperative behaviour, I would have done so.

In this simple episode, problems in our relationship arose as a result of incongruency between two message systems: I refused her hug, yet I was asserting that I liked her very much. Which of the message systems was she to accept?-I said one thing with words and indicated quite the opposite with my gestures. Already I had violated the conversational maxim: "avoid obscurity of expression; avoid ambiguity." In such situations conversational problems arise either because the receiver fails to assign accurate significance to both message systems, or because he/ she does not know to which message system to respond. Conversational rules are, therefore, violated when incongruent message systems are employed in a transaction.

\section{INCONGRUENCY BETWEEN LEVELS OF MEANING}

In conversation, incongruency can equally arise between the denotative and interpretive levels of meaning. A speaker might often say something with the hope that what is said not be interpreted literally. For instance, humour, sarcasm, facetiousness, cattiness and self-deprecation are all verbal behavioral strategies where one level of meaning can negate another. If a conversational partner fails to understand the intention of the speaker 
in saying what he has said, communication difficulties are bound to arise. Incongruencies of this type are probably among the most common in interpersonal communication. Since I don't intend to go into details of this type of incongruency here (see Okolo (forthcoming) for more detailed discussion), I shall only cite an illustrative example.

Two of my colleagues and I were discussing the predicaments of teachers in the light of the current economic difficulties in Nigeria. One of them, a very humorous individual, cut in: "I am so ashamed to be associated with poor people like you; I wish I knew richer human beings!"

At this remark, we all knew that the interpretive level indicated that the denotative level should be taken as a sarcastic or facetious remark, so we had no problems continuing our conversation. But if one or both of us had interpreted the speaker's remarks literally, thereby assigning significance to his utterance, then, it would have become incongruent instead of sarcastic, causing a breakdown in our communication since we would have had difficulties determining his intention. The speaker would have violated the conversational maxim of cooperation: "make your contribution such as required... by the accepted purpose or direction of the talk exchange in which you are engaged" (Grice 1975: 45). However, interactants are usually able to deal with incongruencies of this type without encountering difficulties as long as they are aware of the degree of existing relationships between them.

\section{INCONGRUENCIES AND CONVERSATIONAL MAXIMS}

In discourses, one can provide innumerable examples where participants in a conversation do not adhere to conversational maxims. Although conversations are rulegoverned to a reasonable extent, these rules can often be breached without disrupting the conversation. Probably one of the reasons why discourse studies were neglected for such a long time is the belief that conversational interactions are not as structured as syntactic descriptions, and therefore not subject to rules and constraints that apply in syntactic descriptions. Although this might be true to a certain extent, discourses are highly structured in their own ways and could be described in a formal system if only we realized that particular rules apply to particular discourses in specific situations. As Grice (1975) succintly states, "our talk exchanges do not normally consist of succession of disconnected remarks and would not be rational if they did. They are characteristically, to some degree at least, cooperative efforts; and each participant recognizes in them, to some extent, a common purpose or set of purposes, or at least, a mutually accepted direction" (p. 45).

Incongruencies, though violations of conversational maxims, are not only tolerated in speech, but do not necessarily, in all cases, obstruct healthy communication. Conversational interactions are guided by the existing relationships between the interactants, and these relationships are defined in one way or another before conversations take place. In other words, the territorial parameters of the partners are established even before communication starts, and each partner knows where he/she stands in relation to the parameters before the commencement of the conversation. These parameters are identical to Gricean maxims and to what Heringer (1972) and Lakoff (1977) refer to as politeness phenomena.

The relationship existing between interactants manifests itself in different ways, but in each case, the position of a conversational partner in a particular conversational exchange will not only influence that partner's verbal behaviour, but also will determine whether the conversational maxims are to be strictly adhered to in that exchange or not. It seems that it is the relationship-defining parameter rather than message content that exerts 
greater influence in the application of conversational maxims in discourses. Once this recognition is established, communication is then directed towards and controlled by the established relationship. If this argument holds, then, it becomes easier for us to isolate conversational spheres where Cooperative Principles could be tolerated irrespective of the apparent incongruencies ( $c f$. Okolo 1988).

Violation of conversational maxims may be tolerated in discourses among friends, equals, peers, colleagues, between husband and wife, and the like. Relationship defining parameters permit us to condone or frown at incongruent messages. When two people, who are sufficiently familiar and belong to a particular relationship level, are conversing, problems do not necessarily arise as a result of any incongruencies. Such incongruencies are managed in such a way that healthy communication is still maintained. Even when incongruencies such as sarcasm are hurtful, the existing relationship between them will help to dissolve the hurt, thus repairing the damage that may have been caused in the transaction. In such a situation, any participant can contribute anything without necessarily challenging the structure of the relationship in which the interaction takes place.

On the other hand, conversations involving participants who belong to different relationship levels will be different, for the participants are more likely to frown upon incongruencies that would otherwise have been tolerated were the participants enjoying particular relationship levels. Such incongruencies may be more difficult to repair because the distinctive nature of their individual roles would not allow for violation of conversational rules without affecting the structure of their relationship.

One other factor that can dissolve incongruencies in discourse is context. Conversation is not something that one person does alone; it takes at least two to converse. Furthermore, conversation is situation-specific and verbal strategies employed in one type of discourse may be inappropriate in another. What we do in conversation, therefore, depends, not only on the person with whom we are conversing, but also on the situation. The situation thus helps in placing the speaker's utterances in the right perspective. In a particular situation humor, sarcasm, self-deprecation, etc., could be freely employed without causing any offence, but in solemn and mourning situations incongruent utterances may be unwelcome. In other words, observance of conversational maxims will be obligatory in some situations but flexible or neutralized in others.

Finally, the ability of an interactional partner to recognize the speaker's intent in making an utterance can help in resolving incongruencies. Dore (1979) explains that the speaker's intention produces certain effects on the hearer: the hearer should recognize the status of an incongruent utterance at a particular point in the conversation, and also should be able to recognize how the speaker intends him to react on hearing the utterance. Although it is often difficult to determine the intention of the speaker in any conversational exchange, yet, this recognition is crucial if the hearer must cooperate. Therefore, the hearer must understand the speaker's intention if he violates a particular conversational maxim for that violation to be tolerated.

\section{CROSS-CULTURAL DIMENSIONS OF INCONGRUENCIES}

Several definitions of culture exist, but here, I shall adopt the definition of Spradley (1980: 6) which states that "culture is the acquired knowledge that people use to interpret experience and generate behaviour." In this definition, rather than viewing culture as a list of what people have and do, the focus is on knowledge-what people need "to know or believe in order to operate in a manner acceptable to the members of the culture" (Goodenough 1956: 195). This cognitive or emic definition forces a consideration of the shared symbols that enable people to give form and meaning to their specific experience 
(Geertz 1973). Culture, then, can be viewed as a system of communicative knowledge; all we must know in order to communicate meaningfully.

Sapir (1956: 69) asserts that "no two languages are ever sufficiently similar to be considered as representing the same social reality. The worlds in which different societies live are distinct worlds, not merely the same world with different labels attached." This assertion gives credence to the fact that language and culture are inseparable: language cannot exist without culture and the culture or a people cannot be fully explicated without reference to the language in which it exists. It is the interaction of the two that determines and controls the observance of conversational rules in any particular situation.

Incongruencies as discussed above may not necessarily apply in the same way across cultures because what may be regarded as a violation of conversational maxim in one culture may be the normal in another. Therefore, differences between societies that adhere to the maxim and those that don't may relate to the differences in specifying the domains in which the maxim may hold, and also to the differences in the degree to which participants will abide by the maxim (Okolo 1988). For example, it might even turn out that in a particular culture, in spite of sufficient existing relationship between the interactants, certain incongruent utterances which might be ignored in another culture might be assigned significance in the culture, thereby causing a strained conversational relationship. In societies where power differential external to the conversational is important, it may be regarded as bad manners to make incongruent remarks irrespective of the context and the relationships existing between the individuals. Thus, sarcasm or self-deprecation might not be tolerated by a husband from his wife or children since the society abhors that. In such societies, being a man might imply being serious all the time, not sharing jokes with non-peers, and living in a command-and-obey type of relationship with one's wife and children. Therefore, adhering to conversational maxims in such societies will surely differ from those where the opposite holds.

Thus, it will be seen that although the pragmatic conditions of communicative behaviours are theoretically taken to be universal, the realization of these behaviours as social practices are culturally variable. The variations could be revealed in different cultural assumptions about the situation and about appropriate behaviours and intentions within it, different ways of structuring information or argument in a conversation, and different ways of speaking-the use of different sets of unconscious linguistic conventions (e.g. tone of voice) to emphasize, to signal logical connections and to indicate the significance of what is being said in terms of overall meaning and attitudes (Gumperz 1982).

\section{TRANSLATIONAL IMPLICATIONS OF INCONGRUENCIES}

Translators have long utilized the principles of language analysis in their art, and what became the hallmark of a good translation was an in-depth study of both the source and receptor languages that guaranteed an effective rendition of the intended message. Hence Bassnett-McGuire (1980: 2) states: "what is generally understood as translation involves the rendering of a source language (SL) text into the target language (TL) text so as to ensure that (a) the surface meaning of the two will be approximately similar, and (b) the structure of the SL will be preserved as closely as possible but not so closely that the TL structures will be seriously distorted." In other words, anyone interested in gaining a better understanding of translation norms simply has to learn the SL and TL, and probably a few dos and don'ts in the two languages to become a perfect translator. This approach to translation art has two drawbacks. First, and as observed by Ofuani (1988), this definition is purely dependent on linguistic criteria alone in so far as it solely 
emphasizes "the transfer of meaning contained in one set of language signs into another set of language signs" (p. 389). Secondly, it gives no consideration to the importance of culture and other extra linguistic variables in translation.

The very nature and scope of interpretation settings is such that a translator cannot fail to manifest the shared values, ideas and behaviours prevalent in either the SL or the TL in his art. Although it may be possible for a translator who relies only on linguistic criteria to make significant and valid findings about values or ideas shared by a certain community as to what is right or wrong, adequate or inadequate, the fact still remains that norms, as bound variables of behaviour, exist in interpretation. Ideas are no more implicit than emotions, images and behaviours. Ideas are translatable, but emotions, images and behaviours are not when there are no words to express them. Yet, they inhere in language. Since meaning comes out of a cultural world, the more we know about the cultural background from which the communication emerges and into which we seek to relate the intended message, the more we will be able to mediate the author's intended meaning. A mark of good translation, therefore, necessarily implies knowing what to highlight and what to leave out, and we cannot accomplish this without a proper understanding of the cultural backgrounds of the SL and the TL texts. For example, certain background information which may be shared by members of SL culture may not necessarily be shared by members of the TL culture. To explicate this background knowledge in SL will be unwarranted but to fail to explicate it in TL will be disastrous. Much of the subtlety of meaning that enriches a text can be lost in translation if the translator fails to communicate this implied information. It is, perhaps, with this in mind that Glassgold (1987) considers translation as "a current, a bridge; like a biological process it assimilates or absorbs; it functions as a chemical catalyst, creating communication bonds; it is impossible, or at least so full of snares and traps that it requires military-like strategies to move from a 'source' to a 'target' language" (p. 18).

Incongruencies in discourse, as discussed above, are interactional responses that run counter to co-operative conversational rules, yet, they may be tolerated in conversational exchanges depending on factors external to the linguistic structures in which they occur. Such factors include the relationships existing between the interactants, context, role redefinition and the ability of an interactional partner to determine the intention of the speaker in making an utterance-all factors that are not directly derivable from linguistic structures. Thus, translating incongruent messages poses a problem for the translator whose only yardstick is to match, item-by-item, similar linguistic signals of one language (SL) onto another (TL).

The basic question, then, is: should translators rely only on following some shared model of performance shaped by a fixed set of norms which they have internalized in executing their art, or must they include those extralinguistic factors needed in explicating incongruent utterances for an appropriate rendition of the SL text into the TL text? The answer to the question is obvious: the translator must devise a way of incorporating this extralinguistic information for adequate communication of the message intended, for it is through translation that the assumptions and interests of the author are transformed into a new world. The thoughts, ideas and behaviours expressed take shape only in the linguistic and cultural system in which they were formed. And while language and culture each contribute to our understanding of the Other, both are essential to appreciate the acquired knowledge necessary to act and speak appropriately within a specific context.

Translation norms for literary texts differ from those of oral discourses. Literary translation is not only linguistic but systematic as well, but orally rendered utterances have no clear parameters. Therefore, any attempt to correlate observable differences in performance with the range of existing translation norms for literary material will be 
unworkable. The ability to translate verbal behaviour from one context into another is possible because of common cultural principles that come from sharing the human condition. Meanings of the various cultural forms are held in common by members of a society and may not necessarily be explicit. They constitute, however, that aspect of the culture that embodies the essential concerns and assumptions of a people; what it means to be a member of that society. Therefore, "in considering translation as the primary medium of cultural diffusion, our concern is with the vitality of language and the human community of which it is the quintessential part" (Glassgold 1987:21).

\section{CONCLUSION}

In this limited study, I have tried to identify some of the areas where incongruencies are encountered in discourses. Although incongruencies violate general conversational principles, we are still able to handle them in some discourse situations because healthy interaction presupposes not only the cooperation of interactants engaged in an exchage but also that certain extralinguistic factors are crucial in determining and controlling the direction of any conversational encounter. Cooperation, among other things, implies that we should not judge the speaker solely on the basis of the content of his utterance, but also on the relationship-defining parameters existing between the interactants, the context, role definition, and so on. These extralinguistic variables define the limits of range of specific verbal behaviour that makes conversational strategies possible within a particular discourse situation, and also makes the resolution of incongruent utterances possible.

Incongruencies are culture-specific-what may be tolerated in one culture may be unacceptable in another. Therefore, in regard to violation of conversational maxims, differences in cultural settings may be helpful in determining the domains in which the maxims may hold and also the extent to which participants will abide by them.

Most translational norms seem to overlook the importance of incorporating cultural knowledge in the translation task. Since culture and language are inseparable, a proper rendition of an SL text into a TL text necessarily requires a combination of linguistic and extralinguistic factors that govern conversations without which it will be difficult to fully explicate verbal behavioral utterances that, are violations of conversational maxims, but which nevertheless are, in most situations, tolerated in speech.

Although conversations are rule-governed behavioral acts, the conversational maxims put forth by Grice are not strictly observed in all conversational settings. This study, based solely on incongruencies that apply to a particular cultural community, should serve as an incentive to investigate verbal behavioral acts in other cultural communities. It is only by doing so that we can come up with generalized domains in which Gricean conversational maxims can apply and those in which they cannot. Once this is achieved, it will be easier to formulate translational models and norms that can be generally applied to handle incongruent utterances and achieve a near perfect translation of an SL text into a TL text.

Note

1. An excuse-me dance is a dance in which one may take another's partner.

\section{REFERENCES}

BASSNETT-MCGUIRE, Susan (1980) : Translation Studies, London, Methuen.

BUTTERWORTH, B. and G. BEATIE (1978) : "Gesture and Silence As Indicators of Planning in Speech", R. N. Campbell and P. T. Smith (Eds.), Recent Advances In the Psychology of Language, vol. 4B, New York, Plenum Press, pp. 347-360.

DORE, J. (1979) : "Conversational Acts and the Acquisition of Language", E. Ochs and B. Schieffelin (Eds.), Developmental Pragmatics, New York, Academic Press, pp. 239-362.

GEERTZ, Clifford (1973) : The Interpretation of Culture: Selected Essays, New York, Basic Books Inc. 
GLASSGOLD, Peter (1987) : "Translation: Culture's Driving Wedge", Translation Review, 23, pp. 18-21.

GOLDMAN-EISLER, F. (1958) : "Speech Production and Predictability of Words in Context and Length of Pauses in Speech", Language and Speech, 1, pp. 96-120.

GOODENOUGH, Ward H. (1956) : "Componential Analysis and the Study of Meaning", Language, 32, pp. 195-216.

GRICE, H. P. (1975) : "Logic and Conversation", Peter Cole and Jerry L. Morgan (Eds.), Syntax and Semantics Vol. 3: Speech Acts, New York, Academic Press, pp. 41-58.

GUMPERZ, J. J. (1982) : Discourse Strategies, Cambridge, Cambridge University Press.

HENDERSON, A., GOLDMAN-EISLER, F. and A. SKARBEK (1966) : "Sequential Temporal Patterns in Spontaneous Speech", Language and Speech, 9, pp. 207-216.

HERINGER, J. (1972) : "Some Grammatical Correlates of Felicity Conditions and Presuppositions", Working Papers In Linguistics, $\mathrm{n}^{\circ} 11$, Columbus, Ohio, Ohio State University, pp. 1-110.

LAKOFF, R. (1977) : "Language and Society", R. Wardaugh and H. D. Brown (Eds.), A Survey of Applied Linguistics, Ann Arbor, The University of Michigan Press, pp. 207-228.

OFUANI, Ogo A. (1988) : "Linguistic Expediency and/or The Quest for a Poetic Mode: Translation Strategies in Okot P'Bitek's Poetry", Meta, 33-3, Montréal, pp. 388-397.

OKOLO, B. A. (1988) : "Discourse Implicatures: An Ibgo Example", Journal of West African Languages, XVIII, 1, pp. 89-96.

OKOLO, B. A. (forthcoming) : "Indirectness in Discourse: A Study in Paradoxical Communication Among the Igbos", to appear in Language and Style.

PRATT, M. L. (1977) : Toward A Speech Act Theory of Literary Discourse, Bloomington, Indiana, University Press.

SAPIR, Edward (1956) : Culture, Language and Personality, Berkeley, Los Angeles, University of California Press.

SMITH, D. R. and L. K. WILLIAMSON (1977) : Interpersonal Communication, Iowa, William C. Brown and Company Publishers.

SPRADLEY, James P. (1980) : Participant Observation, New York, Holt, Rinehart and Winston. 